(0)

.

This is a preprint (pre-peer reviewed) version of the following paper: "Chiara Venier, Stefano Menegon, Hugh P. Possingham, Elena Gissi, Andrea Zanella, Daniel Depellegrin, Alessandro Sarretta, Andrea Barbanti, Jennifer McGowan, Multi-objective zoning for aquaculture and biodiversity", in Science of the Total Environment, Volume 785 (2021) 146997 https://doi.org/10.1016/j.scitotenv.2021.146997.

\title{
Multi-objective zoning for aquaculture and
}

\section{biodiversity}

\author{
Chiara Venier ${ }^{a, b, *}$, Stefano Menegon ${ }^{b,{ }^{*}}$, Hugh P. Possingham ${ }^{c, d}$, Elena Gissi ${ }^{e}$, Andrea Zanella ${ }^{f}$, \\ Daniel Depellegrin', Alessandro Sarretta ${ }^{h}$, Andrea Barbanti $^{b}$, Jennifer McGowan $^{c, d}$

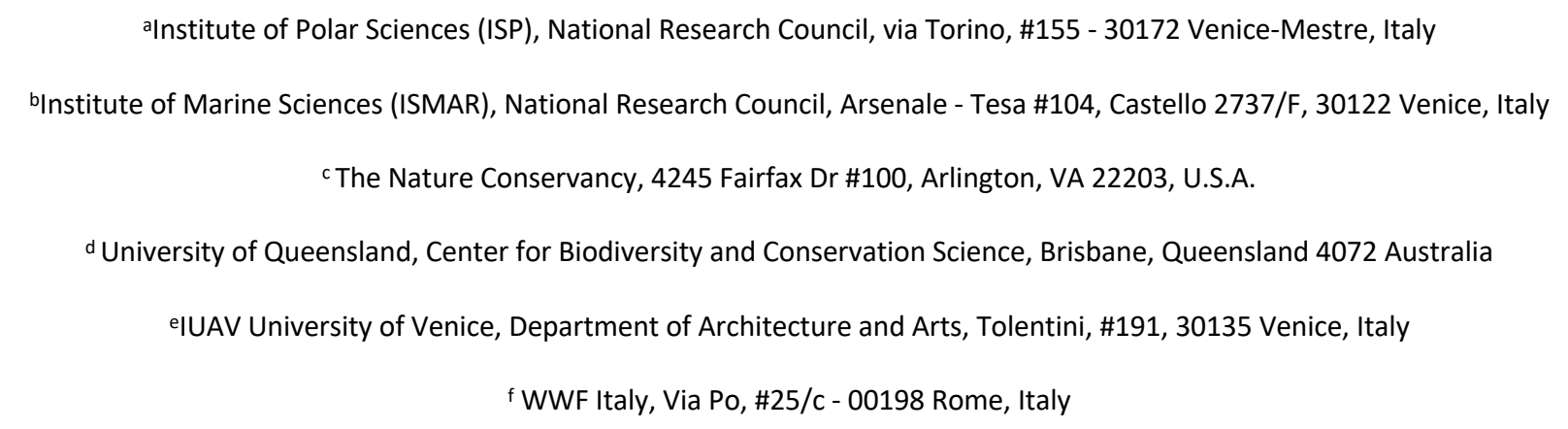




\section{Graphical Abstract}

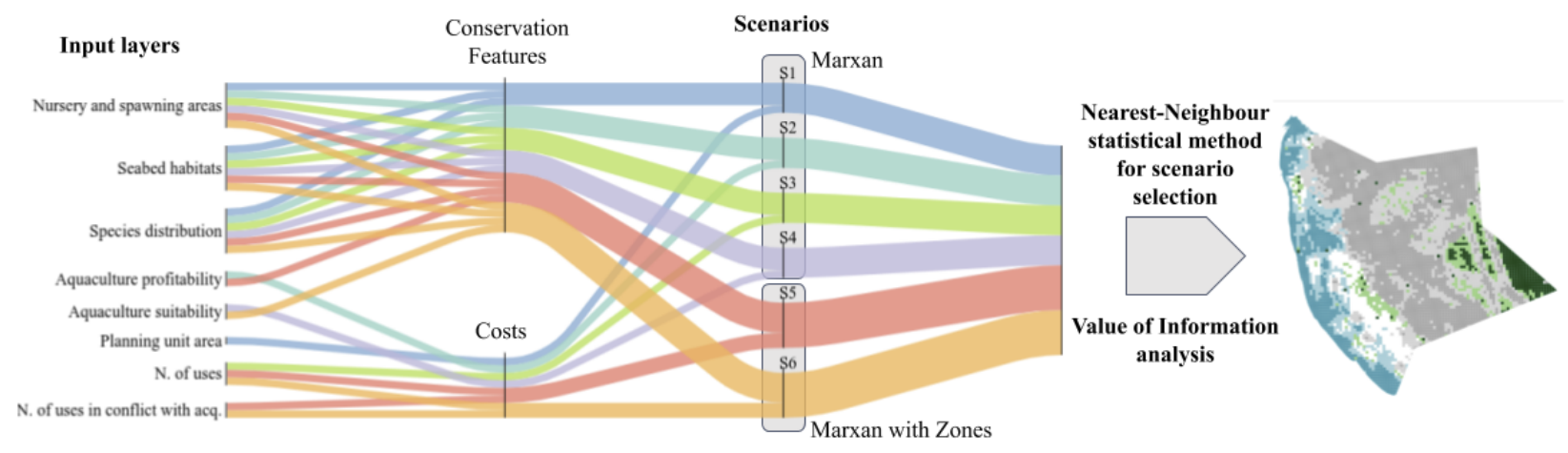

\section{Abstract}

28 Aquaculture is the fastest growing food production industry in the world yet research and guidance

29 demonstrating strategic multi-objective zoning for sector expansion is scarce. Quantifying and mitigating

30 conflicts and impact on sensitive coastal environments through jointly-optimized objectives for

31 aquaculture and biodiversity simultaneously has not been tested yet.

32 We here develop and evaluate six alternative planning scenarios for one of the European Union's highest

33 priority mussel aquaculture areas, the Emilia-Romagna Region in Italy. We i) develop an aquaculture

34 profitability surface as a function of the distance from main ports, and in parallel build a fine-scale

35 aquaculture suitability distribution surface for important commercial species using multi-criteria analysis;

36 ii) prioritize protected areas for biodiversity while testing how different considerations of human impacts

37 influence priorities; iii) simultaneously plan for aquaculture and biodiversity while minimizing impacts on

38 other maritime activities. We compare results from different scenarios according to how well they capture

39 suitable aquaculture habitats and minimize impacts. We introduce a new evaluation method for scenario

40 comparison in spatial optimization using a nearest-neighbour analysis for spatial pattern similarities. 
41 Lastly, we test the "value of information" provided by our investment in developing the fine-scale

42 suitability surface to improve efficiencies.

43 We find that an integrated multi-objective zoning approach, which simultaneously optimizes for

44 biodiversity and aquaculture, supports more efficient planning than traditional sector specific growth

45 strategies. We also discovered that the fine-scale suitability model delivered an $8 \%$ more efficient solution

46 than the simple distance function, highlighting the role of proxy surfaces and diminished returns from

47 investing in comprehensive habitat suitability analysis in regions without much variation in key 48 parameters.

49 We offer evidence of improved efficiency and practical guidance for integrated planning in Blue Growth

50 agendas. Our analysis can be applied in any context where multiple objectives occur for aquaculture sector

51 growth and biodiversity conservation.

52

53 Keywords: Biodiversity Conservation, Maritime Spatial Planning, Marxan and Marxan with Zones, Multi-

54 objective Zoning, Sustainable Aquaculture Development, Value of Information.

55

56 


\section{Introduction}

58 Aquaculture is the fastest growing form of food production on the planet, growing at an annual rate of

$596 \%$ per year (FAO 2015; Froelich et al. 2018, O'Shea et al. 2019). Significant expansion of aquaculture in

60 the Mediterranean is a primary component of the European Union's Blue Growth Initiative (Blue Growth

61 Initiative, DG MARE 2012), of the Adriatic and Ionian Macro-regional strategy (EC 2014a) and of the

62 Maritime Spatial Planning (MSP) Directive 2014/89/EU (EC 2014b). The coastal waters of the northern

63 Adriatic Ionian Region of Italy, in particular the Emilia-Romagna region, are a priority for aquaculture

64 development (EC 2008; Barbanti et al. 2018). This region produces $45 \%$ of the national production of clams

65 (Tapes philippinarum) and mussels (Mytilus galloprovincialis) - approximately 40,000 tons/year (Mipaaf

66 2015). National planning requires the identification of proposed areas of interest for the development

67 and expansion of the aquaculture sector based on their environmental suitability, conflicts and synergies

68 with other uses, as well as proximity to port infrastructure (Barbanti et al. 2018).

69

70 Biodiversity protection is also a fundamental component of the EU-MSP Directive and the Adriatic lonian

71 Sea is recognized as an Ecologically and Biologically Significant Marine Area (EBSA) (Johnson et al. 2018,

72 Giakoumi et al. 2013). Coastal waters contain valuable Essential Fish Habitats that provide resources and

73 nursery grounds to both vulnerable species, such as the Atlantic horse mackerel, and commercially

74 important species such as anchovies (e.g., Engraulis encrasicolus) and sole (Solea solea) (Grati et al. 2013).

75 Additionally, these waters host bottlenose dolphin (Tursiops truncatus) and provide one of the most

76 important feeding grounds in the Mediterranean for the endangered Loggerhead sea turtle (Caretta

77 caretta). 
79 Reconciling the need for biodiversity protection alongside economic growth from aquaculture in Emilia-

80 Romagna must also consider human uses co-occurring in the region. These include coastal and maritime

81 tourism, which is the primary economic activity, as well as port activities, shipping of goods and

82 passengers, commercial and recreational fisheries, energy and communication infrastructure, military

83 uses, sand extraction, underwater cultural heritage sites, and offshore gas and oil platforms (the region

84 alone contributes roughly 50\% of the national gas supply (Assomineraia, 2015). Thus, developing marine

85 spatial planning strategies that can identify suitable sites for aquaculture expansion, while not

86 compromising important areas for biodiversity and other socio-economic uses in the region, is a complex

87 but essential priority (Gissi et al. 2018; Mazor et al. 2014; Farella et al. 2020; Henriques et al. 2017;

88 Fernandes et al. 2018).

90 There are many examples of multi-objective marine spatial planning approaches (Beger et al. 2015) that

91 balance biodiversity with industry and other human activities (Klein et al. 2008; Jumin et al. 2018; Yates

92 et al. 2015; Grantham et al. 2013) but these typically focus on developing zoning plans that retain existing

93 fishing grounds. Currently, there is limited guidance for planning the expansion of aquaculture in coastal

94 habitats while balancing the needs of biodiversity and managing conflicts with other uses. We fill this gap

95 by proposing a comprehensive analysis that develops and tests six planning scenarios in the Emilia-

96 Romagna region of Italy. These scenarios increase in complexity from traditional approaches that

97 prioritize biodiversity alone, while minimizing impacts on human activities, through to multi-objective

98 prioritization for both biodiversity and aquaculture.

99

100 Prioritizing new locations for aquaculture requires an understanding of the environmental, biophysical

101 and economic constraints influencing suitability. Thus, we conduct a comprehensive suitability analysis

102 for the target aquaculture species (Stelzenmüller et al. 2017), but also test the value of this information 
103 to inform priorities against a profitability assessment driven by distance to the coastline (Mazor et al.

104 2016; Jumin et al. 2018. We use the decision support tool Marxan (Ball and Possingham 2000), as well as

105 its advanced version, Marxan with Zones (Watts et al. 2009), to identify priority areas for aquaculture

106 and/or conservation. We evaluate our results in two ways. Firstly, we look at the aquaculture area

107 prioritized across all scenarios and zoning configurations. Secondly, we develop a new comparative

108 method to examine the similarities of the spatial configurations of zoning solutions in addition to their

109 levels of priority. This method calculates pairwise similarity between scenarios and randomly generates

110 solutions in order to quantify observable differences in spatial priorities. Given the important and

111 increasing role aquaculture will play in global food production (Gentry et al. 2017), our aim is to provide

112 the first practical exploration of how to conduct and evaluate multi-objective prioritization for

113 aquaculture and biodiversity using a systematic planning approach.

114

115

116

117 


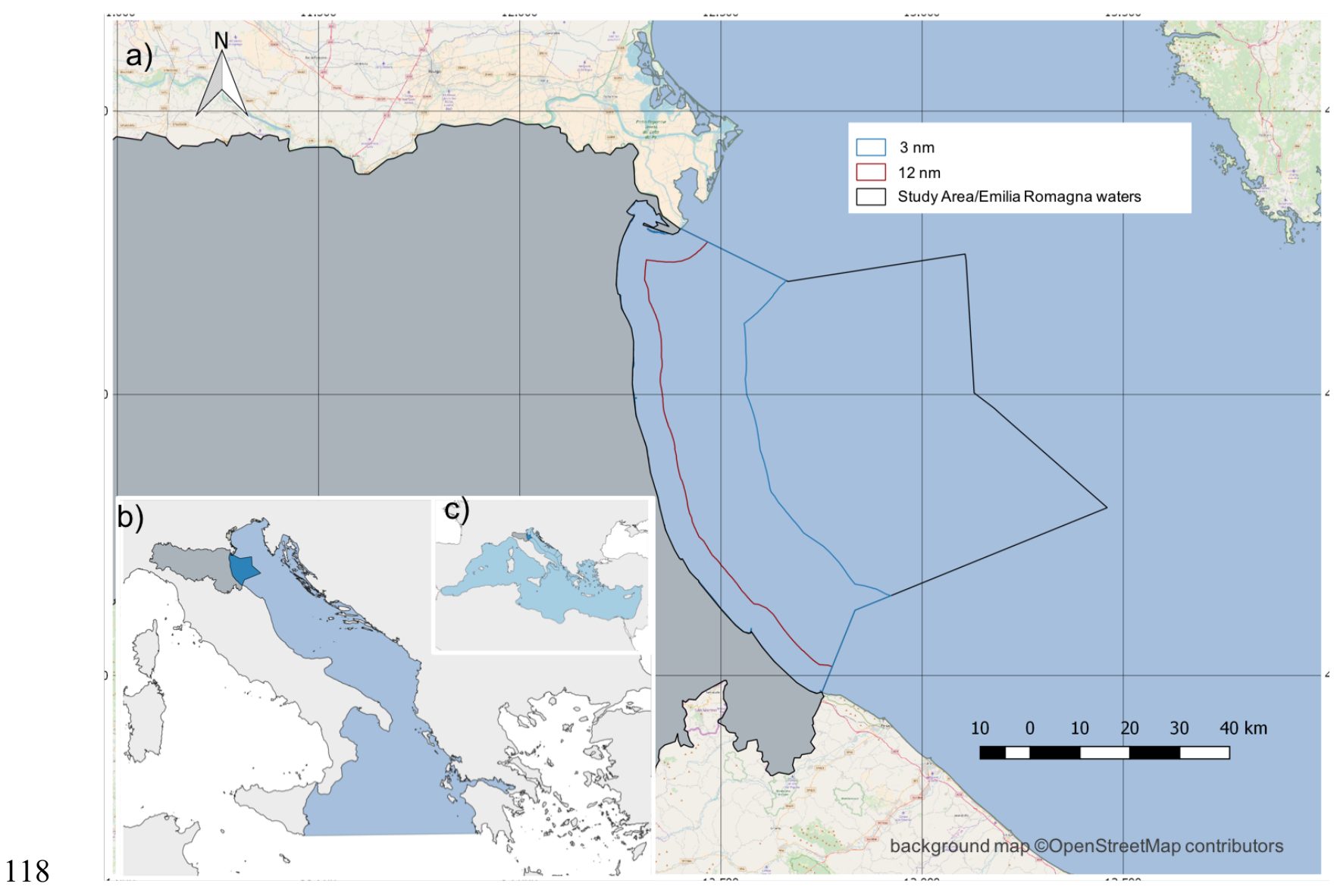

119 Figure 1: Study Area boundaries (a) and their location in the Adriatic Sea (b) and in the Mediterranean Sea (c) context. 


\section{Material and Methods}

\section{$125 \quad 2.1$ Study Area and Design}

126 The planning area spans on the Emilia-Romagna marine waters $\left(5256 \mathrm{~km}^{2}\right)$, from the coast (approximately

$127120 \mathrm{~km}$ in length) up to the limit of Italian jurisdictional waters, including the territorial sea and high seas

128 up to the midline (approximately $70 \mathrm{~km}$ ), which is the international waters limit (see Figure 1). The 129 planning area was divided into 5,256 square planning units of $1 \mathrm{~km} \times 1 \mathrm{~km}$ size.

131 Our study design consists of three main steps performed consecutively (Appendix S.1 in the Supporting

132 Information). Firstly, we organize and develop the three classes of spatial data layers required to underpin

133 the analyses, which include: i) relevant conservation features (e.g. habitats and species); ii) aquaculture

134 suitability and profitability surfaces; and iii) distributions of human activities and industries. Secondly, we 135 construct six planning scenarios using different treatments of the three classes of data to identify priorities 136 in either single objective plans using Marxan, or multi-objective plans using Marxan with Zones. Lastly, we 137 conduct post-hoc evaluations across all scenarios using suitability analysis and a spatial similarity analysis 138 based on a new analytic method.

\section{$141 \quad$ 2.2.1 Conservation Features}

142 We included 33 conservation features (Appendix S.2) based on regional spatial data provided in the 143 Tools4MSP Geoplatform - the primary platform developed to support marine spatial planning in the 
144 Adriatic Sea (data.tools4msp.eu) (Menegon et al. 2018). The features include seabed habitats (maerl bed,

145 infralittoral fine sands, circalittoral fine sands, circalittoral sandy mud, circalittoral fine mud) (European

146 Environmental Agency 2017), and data for important species including: bottlenose dolphin (Tursiops

147 truncatus), seabirds and loggerhead sea turtles (Caretta caretta) species distributions, and nursery and

148 spawning areas of commercially important fish species (Engraulis encrasicolus, Mullus barbatus, Pagellus

149 erythrinus, Sardina pilchardus, Scomber colias, Scomber scombrus, Solea solea, Trachurus mediterraneus,

150 Trachurus trachurus).

$152 \quad$ 2.2.2 Aquaculture suitability

153 Developing a spatial understanding of where conditions are most suitable for the three most commercially

154 important species of mussels, Crassostrea gigas, Mytilus galloprovincialis, and Ostrea edulis, is required

155 before priority areas for aquaculture expansion can be identified. To do so, we followed the methods

156 outlined in existing literature to derive aquaculture suitability scores (Valentini et al. 2016; Davaasuren et

157 al. 2010; Andersen et al. 2013), which we then vetted with national aquaculture experts. This process

158 defines eleven important indicators related to three criteria: environmental quality, optimal mussel

159 growth conditions and socio-economic considerations (Appendix S.3). We assume suitability scores of 0.6

160 or higher reflect sufficient environmental quality for mussel growth (Arpae, 2017; Dapueto et al., 2015).

162 Weights for all criteria (Appendix S.3) were assigned according to previous work by Dapueto et al. (2015).

163 The suitability (S) for each planning unit (i) was calculated according to the following equation (Appendix

164 S.4.a):

165

$166 S_{i}=\sum_{j} w_{j} c_{i j}$

(Eq. 1) 
168 where:

$169 \mathrm{i}=\mathrm{i}$-th planning unit,

$170 \mathrm{j}$ = criteria (environmental quality, optimal mussel conditions and socio-economic aspects),

$171 \mathrm{w}_{\mathrm{j}}=$ weight of the $\mathrm{j}$-th-criteria, and

$172 \quad c_{i j}=$ scores of the indicators.

173

174 The primary socio-economic factor considered was the distance of a planning unit to any port, as we

175 assume aquaculture zones placed further away from shore will decrease net profits due to the operational

176 costs of travel (Mazor et al. 2014). To calculate the value, we used the following equation to build the

177 proxy profitability surface:

178

179

$P=\max (1-\alpha d, 0)$

(Eq. 2)

181 where the proxy profitability (P) of a planning unit is determined by the parameter $\alpha$ which reflects how

182 fast profitability declines as the facility moves from the coast. Coastal areas near ports have a shorter

183 distance to travel, thus the management cost for the industry (e.g. fuel, vessel maintenance, etc) is

184 considered marginal closer to the coast and increases with distance. We assume aquaculture would no 185 longer be profitable in the area outside of $12 \mathrm{~nm}$ (Appendix S.4b).

186

\section{2.2.3 Human Use layer}

188 To generate a cost surface reflective of human uses, we follow the method of Gissi et al. 2018, which used 189 the number of maritime industries occurring in each planning unit as a proxy for the transaction costs of 
191 (Appendices S.5 and S.6). We included the distributions of 12 industrial sectors and activities, as mapped

192 by Tools4MSP Geoplatform (Menegon et al. 2018): aquaculture, coastal and maritime tourism, coastal

193 defence works, dumping area for dredging, maritime transport, military areas, naval-based activities, off-

194 shore sand deposit, oil and gas extraction, oil and gas research, small-scale fisheries, and commercial

195 fishery (Appendix S.5a). We assumed that all maritime industries have equal standing in the negotiation

196 process and thus did not add an arbitrary weighting to the aggregate values. We also created a variation

197 of this cost surface that included a total of 7 uses considered to be in conflict with aquaculture, specifically

198 (Appendix S.5b).

\subsection{Scenarios and Prioritization}

201 Reconciliation of competing human uses lay at the center of marine spatial planning challenges in the

202 Adriatic Sea (Gissi et al. 2018). Therefore, we were primarily interested in understanding how priorities

203 for biodiversity and aquaculture changed depending on the treatment of human uses and industries used

204 in the prioritization analysis. We used the spatial decision-support tools Marxan (Ball and Possingham

205 2000) and Marxan with Zones (Watts et al. 2009), which use a simulated annealing algorithm to meet

206 predetermined targets for conservation features whilst minimizing impacts (also termed "costs") to

207 industries. We used different combinations of objectives, targets, Marxan softwares, and costs to develop

208 six planning scenarios (Table 2). To make our comparisons as objective as possible, we did not apply the

209 boundary length modifier in our analyses to preference compactness.

210

211 Table 2: Scenario construction describing how objectives, tools, targets, and costs vary across the six 212 analyses. 


\begin{tabular}{|c|c|c|c|}
\hline Objective & Scenario & Conservation Features and Targets & Cost Used \\
\hline \multirow{4}{*}{$\begin{array}{l}\text { Biodiversity } \\
\text { Prioritization } \\
\text { (Marxan) }\end{array}$} & S1 & \multirow{4}{*}{$\begin{array}{l}\text { - Seabed habitats }(30 \%) \\
\text { - Nursery and spawning areas }(30 \%) \\
\text { - Species distribution }(10 \%)\end{array}$} & Area \\
\hline & S2 & & $\begin{array}{l}\text { Aquaculture } \\
\text { profitability }\end{array}$ \\
\hline & S3 & & $\begin{array}{l}\text { Number of human } \\
\text { uses }\end{array}$ \\
\hline & S4 & & Aquaculture suitability \\
\hline \multirow{4}{*}{$\begin{array}{l}\text { Biodiversity } \\
\text { and } \\
\text { Aquaculture } \\
\text { Prioritization } \\
\text { (Marxan with } \\
\text { Zones) }\end{array}$} & \multirow{3}{*}{ S5 } & $\begin{array}{l}\text { Biodiversity zone (S5Z1) } \\
\begin{array}{l}\text { - Seabed habitats (30\%) } \\
\text { - Nursery and spawning areas (30\%) } \\
\text { - Species distribution (10\%) }\end{array}\end{array}$ & $\begin{array}{l}\text { Number of human } \\
\text { uses }\end{array}$ \\
\hline & & $\begin{array}{l}\text { Aquaculture zone (S5Z2) } \\
\text { - Aquaculture profitability (40\%) }\end{array}$ & $\begin{array}{l}\text { Number of uses in } \\
\text { conflict with } \\
\text { aquaculture }\end{array}$ \\
\hline & & $\begin{array}{l}\text { Multiple-Use (S5Z3) } \\
\text { - No targets set }\end{array}$ & $\begin{array}{l}\text { Number of human } \\
\text { uses }\end{array}$ \\
\hline & S6 & $\begin{array}{l}\text { Biodiversity zone (S6Z1) } \\
\text { - Seabed habitats (30\%) } \\
\text { - Nursery and spawning areas (30\%) } \\
\text { - Species distribution (10\%) }\end{array}$ & $\begin{array}{l}\text { Number of human } \\
\text { uses }\end{array}$ \\
\hline
\end{tabular}




\begin{tabular}{|l|l|l|}
\hline & $\begin{array}{c}\text { Aquaculture zone (S6Z2) } \\
\bullet \quad \text { Aquaculture suitability (40\%) }\end{array}$ & Number of uses in \\
& conflict with \\
\cline { 3 - 4 } & $\begin{array}{c}\text { Multiple-Use zone (S6Z3) } \\
-\quad \text { No targets set }\end{array}$ & Number of human \\
\hline
\end{tabular}

\section{2.3.1 Single-objective scenarios using Marxan}

216 Important conservation features were assigned a 30\% target in accordance with the world's oceans target

217 established at the IUCN World Conservation Congress in Hawaii (2016). We also set $10 \%$ targets for broad

218 ranging species distributions in line with Aichi 11 Target under the Convention on Biological Diversity

219 (2010). For the first four scenarios, we kept these targets consistent while we varied the way in which the

220 cost of a planning unit was calculated. The costs for the four scenarios were: S1) area of the planning unit

221 - a baseline approach to set equal costs across the planning region so that priorities are solely determined

222 by the conservation features, S2) aquaculture profitability based on the distance to port function, S3)

223 human uses based on the number of maritime activities found in a planning unit and S4) the aquaculture

224 suitability surface.

\section{2.3.2 Multi-objective scenarios using Marxan with Zones}

227 We then developed two additional multi-objective prioritization scenarios (S5 and S6) aimed at 228 simultaneously meeting targets for biodiversity and aquaculture whilst minimizing costs to maritime 
229 industries. Marxan with Zones allows for more sophisticated planning problems than standard Marxan,

230 allowing users to make specific allocations of features, targets and costs to different more than just one

231 kind of zone (Watts et al. 2009; Klein et al. 2010). We organized this analysis around three zones:

232 Biodiversity (Zone 1) with the aim of conserving our biodiversity features; Aquaculture (Zone 2) with the

233 aim of capturing suitable sites for aquaculture; and Multiple-Use (Zone 3) where any activity can take

234 place, but which has no biodiversity or aquaculture targets set. We kept the biodiversity targets consistent

235 with the single objective scenarios for the biodiversity zone, set targets for $40 \%$ for the Aquaculture Zone,

236 applied to the profitability surface used in Scenario 5 (S5Z2) and the suitability surface used in Scenario 6

237 (S6Z2). We also applied two different treatments of the human use cost surfaces, using all human uses in

238 the Biodiversity and Multiple-Use Zones and human uses deemed incompatible with aquaculture in the 239 Aquaculture Zone (Table 2).

\section{$241 \quad 2.4$ Scenario Comparisons}

242 Marxan returns two major outputs: the individual solutions from each run (total of 100 runs per scenario

243 in this analysis), from which one is determined the "best solution" by achieving the lowest Marxan score;

244 and the "selection frequency" - the frequency with which any planning unit is selected from 100 good 245 solutions. A selection frequency of 100 means a planning unit was in all 100 good solutions and is deemed 246 irreplaceable in order to achieve your objectives (Smith et al. 2019).

248 To compare scenarios, we were interested in understanding how the different cost surfaces (e.g. area, 249 profitability, suitability and human uses) performed at minimizing impacts to the most suitable areas for 250 aquaculture expansion, particularly within the $12 \mathrm{~nm}$ limit where aquaculture industries can operate. To 251 analyze this, we took the portfolio of solutions for each scenario, assigned the aquaculture suitability value 
252 to the selected planning units and evaluated the mean of such values. We refer to this as the "suitability

253 footprint" of the solution (Appendix S.7). Boxplots and histograms of the suitability footprints for 254 scenarios allow us to understand how our decisions on cost considerations impact our planning results.

256 Examining how the best solution or selection frequency changes from scenario to scenario is a common 257 way to evaluate differences across scenarios. This is often done graphically by identifying where planning 258 unit selection diverges or remains the same between two scenarios. Another method is to use statistical 259 analyses such as calculating the Jaccard statistic (Real and Vargas 1996) or performing hierarchical 260 clustering (Harris et al. 2014). One limitation of these approaches is that they do not provide insight into 261 how similar the spatial configuration of selected planning units may be. Thus, two solutions may have very 262 similar prioritization patterns in a region, but if the selected planning units are slightly shifted in space, 263 the similarity analysis results can be misleadingly low. In order to overcome this limitation, we developed 264 a method to evaluate the patterns of spatial priorities, in addition to standard comparison methods, for 265 every pairwise scenario, for all 15 comparisons.

267 We adapted the Nearest Neighbor Analysis approach (Ebdon, 1991), normally used for single scenario 268 analysis, to investigate the similarity in the spatial configuration across scenarios.

269 The best solution outputs from each scenario have been used to compute the Nearest Neighbour ratio 270 index (Eq.3), testing the performance of this approach, according to the following steps:

271 - Firstly, we compute the average of the minimum distance distributions between the centroid of 272 a selected planning unit of one scenario and the centroid of the closest selected planning unit of 273 the other scenario, $\mathrm{NN}(\mathrm{Sx}, \mathrm{Sy})$, where $\mathrm{x}$ and $\mathrm{y}$ denote two separate solutions (plans). 
- considering that nearest neighbour distance is asymmetric, in most cases $\mathrm{nn}(\mathrm{Sx}, \mathrm{Sy})$ (forward) is not equal to $n n(S y, S x)$ (backward), we define the Nearest Neighbor distance (NN) as the maximum over these distances (forward and backward).

- Finally, the NN ratio is calculated as the observed NN distance divided by the expected NN based on the hypothetical randomized solutions of both scenarios with the same number of selected planning units $(\underline{N N})$.

$281 \quad$ NNratio $x y=\frac{N N(S x, S y)}{\underline{N N}(S x r, S y r)}$

283 with

$$
N N(S x, S y)=\max \{n n(S x, S y), n n(S y, S x)\}
$$

$n n(S x, S y)=\frac{\sum_{i \in S x} \min _{j \in S y} d_{i, j}}{n}, n n(S y, S x)=\frac{\sum_{j \in S y} \min _{i \in S x} d_{i, j}}{m}$,

287 where:

$288 \mathrm{n}=$ total number of selected planning units for scenario Sx,

$289 \mathrm{~m}=$ total number of selected planning units for scenario Sy, and

$290 \mathrm{~d}_{\mathrm{i}, \mathrm{j}}=$ distance between planning unit $\mathrm{i}$ of scenario Sx and planning unit $\mathrm{j}$ of scenario Sy.

292 If the index is less than 1 , the two scenarios exhibit more similarity in their patterns than random. If the 293 index is greater than 1, the patterns are more dissimilar than random.

295 To evaluate this new Nearest Neighbor method, we also calculated the Jaccard distance (0 (full similarity) 296 to 1 (no similarities)) for each pairwise scenario, defined as the ratio of the size of the symmetric difference 297 between scenarios to their union (Real and Vargas 1996). We compute (see Eq.4) how many times the 
298 planning units have been selected in just one of two scenarios compared and divided this value by the 299 total number of selected units (excluding the combination 0-0) to derive the Jaccard ratio:

300

$301 \quad$ Jaccard ratio $_{x y}=\frac{J(S x, S y)}{J(S x, S y)}$

302

303 where Jaccard distance $(\mathrm{J})$ is divided by the expected Jaccard mean distance given from random patterns $304 \quad(J)$ for two scenarios.

305

306 We plot the NN ratio and Jaccard ratio for each pairwise comparison in order to explain the similarity and

307 dissimilarity between their spatial patterns. For this method, the lower the NN and Jaccard ratios, the 308 more similar the two solutions are.

309 


\section{3. Results}

\subsection{Scenarios analysis}

313 Across the biodiversity prioritization scenarios (Figure 2; S1-4; Table 2), the areas identified for protection

314 were heavily influenced by the spatial distributions of the cost surfaces. When we used area as a cost (S1),

315 priorities for protection were uniformly distributed across the region because solutions are not bound by

316 variations in the cost surface and biodiversity targets could easily be met throughout the planning region.

317 More definitive priorities emerge in Scenarios S2-S4 with the introduction of spatial variation in costs.

318 Aggregations of high priority areas near the city of Ravenna and along the $12 \mathrm{~nm}$ boundary emerge where

319 impacts to aquaculture profitability (S2) and suitability (S4) are minimized. Consideration of human

320 activities (S3) constrains the pelagic areas outside of $12 \mathrm{~nm}$, evidenced by the clear avoidance of linear

321 shipping lanes in the southwest region. In all cases, targets for both important nearshore habitats and

322 more broadly distributed pelagic features can be met with a high level of flexibility across the region

323 (Appendix S.8) and the area needed to meet these targets covers around $30 \%$ of the planning region. 
S1

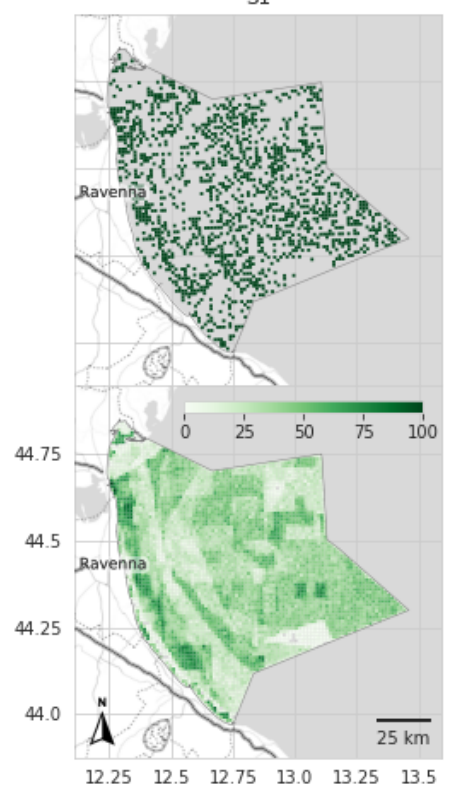

S2

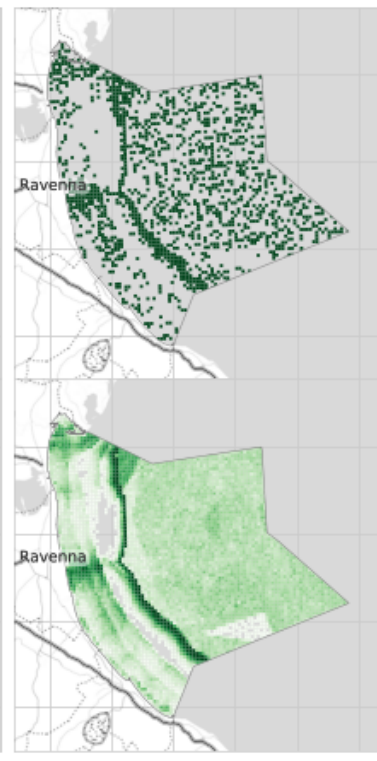

$\mathrm{S3}$

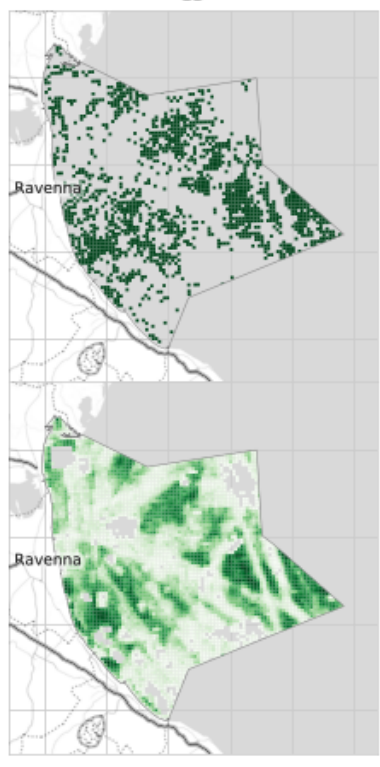

S4

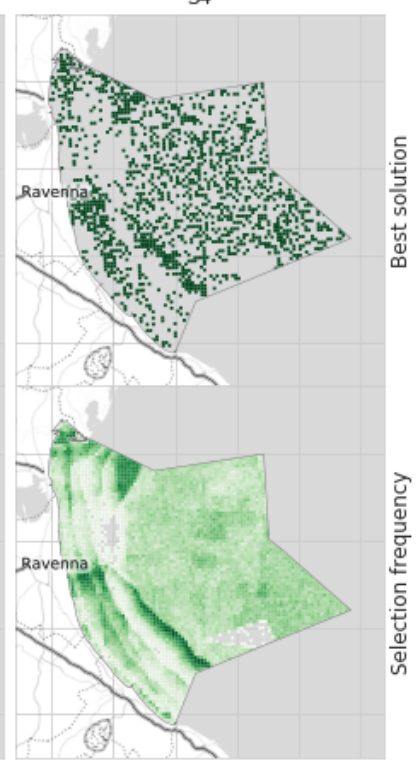

Figure 2: Results from scenarios 1-4 showing the best solutions (top row) and selection frequencies

327 (bottom row) where the cost surface changes. 
S5

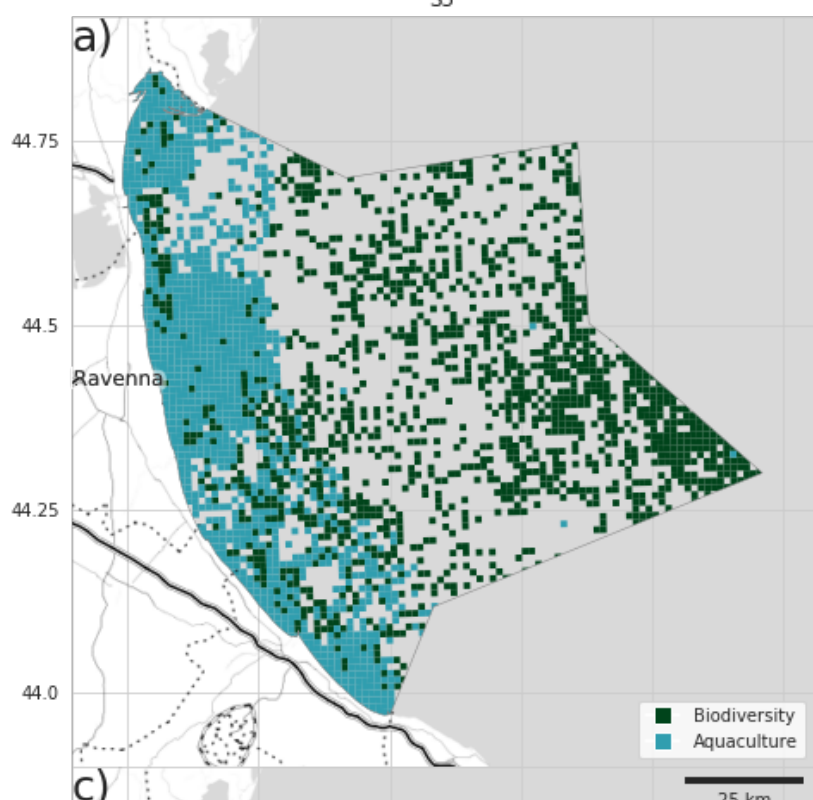

c)

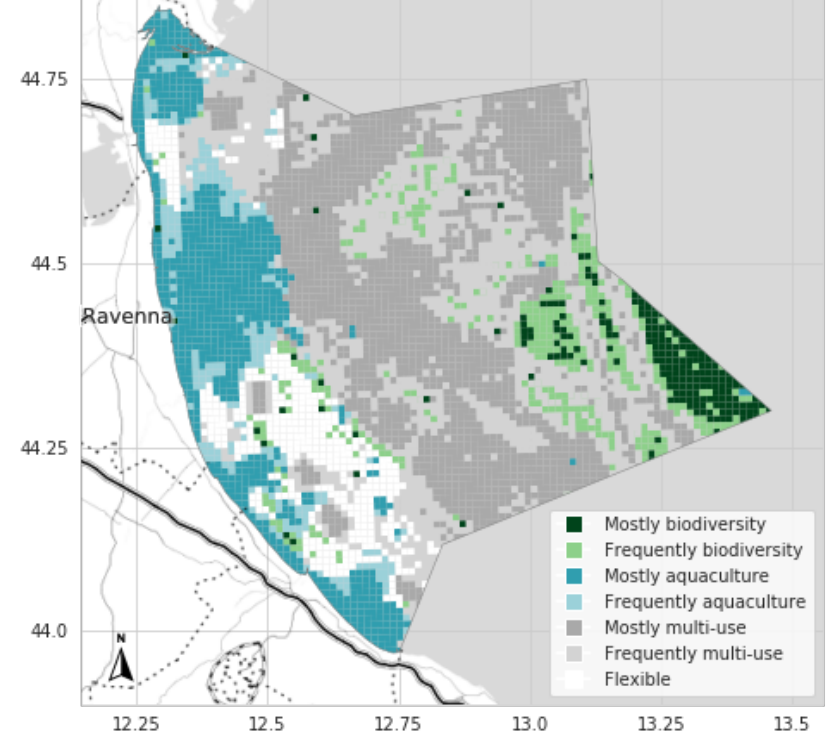

S6

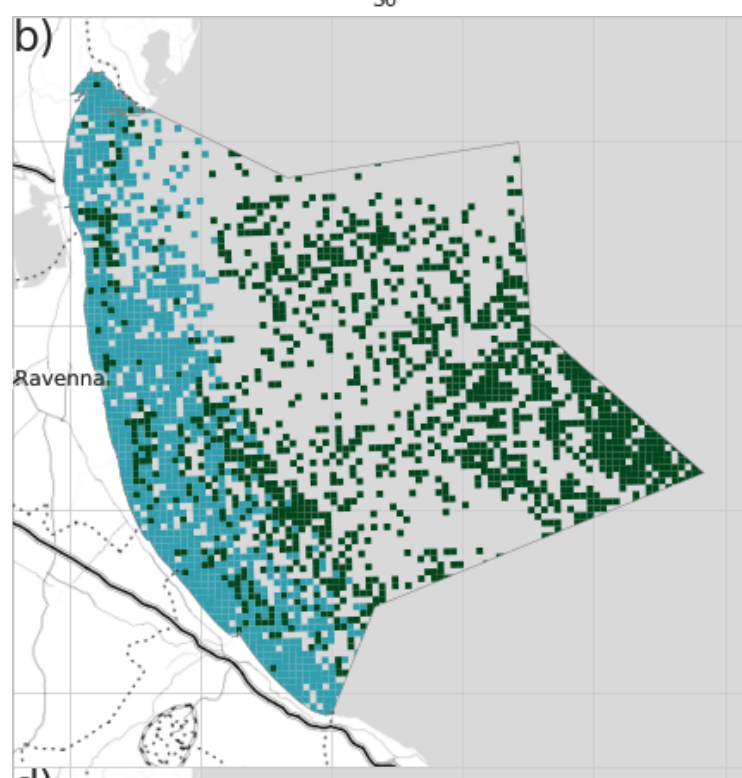

d)

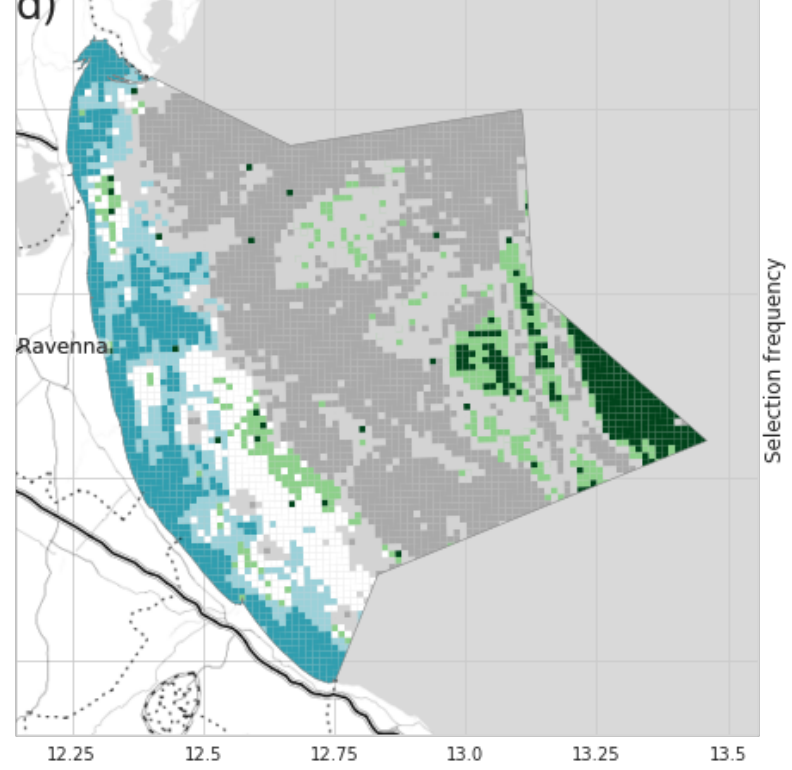

333 Figure 3: Top row - Best Solution results for a) scenario 5 and b) scenario 6. Bottom row - Selection

334 Frequency (SF) results for c) scenario 5 and d) scenario 6, where: Mostly biodiversity (dark green), when

335 SF biodiversity >= 70\%; Frequently biodiversity (light green), when SF biodiversity between 50\% and 70\%;

336 Mostly aquaculture (dark blue), when SF aquaculture >= 70\%; Frequently aquaculture (light blue), when

337 SF aquaculture between 50\% and 70\%; Mostly multi-use (dark grey), when SF multi-use >= 70\%; Frequently

338 multi-uses (light grey), when SF multi-use between 50\% and 70\%; Flexible (white), when the difference 
among the three zones is less than $15 \%$.

341 Best solutions from the multi-objective scenarios (Figure 3; S5-S6) show the nearshore coastline as the 342 most preferred placement for aquaculture, with biodiversity objectives needing to be met throughout.

\subsection{Scenario comparisons using the suitability footprint}

345 Projecting the aquaculture suitability footprint onto the solutions prioritized for biodiversity shows that,

346 in general, locations identified for biodiversity conservation in the basic Marxan approach occupy more

347 of the suitable aquaculture areas relative to the multi-objective Marxan with Zones-based approach. For

348 example, the aquaculture suitability footprint of the solutions (Appendix S.7) ranged from 0.25 to 0.27 for

349 the single-objective scenarios (S1-S4) but was reduced to 0.21 when biodiversity and aquaculture were

350 simultaneously prioritized (S5-S6) (Appendix S.9). When we prioritized for both objectives simultaneously,

351 the average suitability footprint in the aquaculture zones ranged from 0.55 (S5) to 0.58 (S6) (Appendix

352 S.9).

354 Histograms of the best solutions for each scenario show the number of planning units prioritized for

355 biodiversity and their corresponding aquaculture suitability values within the $12 \mathrm{~nm}$ coastal area (Figure

356 4). We found the scenarios that used the aquaculture-related cost surfaces for profitability (S2) and

357 suitability (S4) met biodiversity priorities by selecting more planning units in the $6-12 \mathrm{~nm}$ area, where

358 aquaculture suitability is lower, than scenarios that used the non-aquaculture related costs: area (S1) and

359 human impacts (S3). The biodiversity zones in the multi-objective prioritizations were the most efficient

360 at avoiding suitable aquaculture habitat, using less overall area to meet biodiversity priorities in the 
362 places for aquaculture than any of the single objective scenarios.

363

364
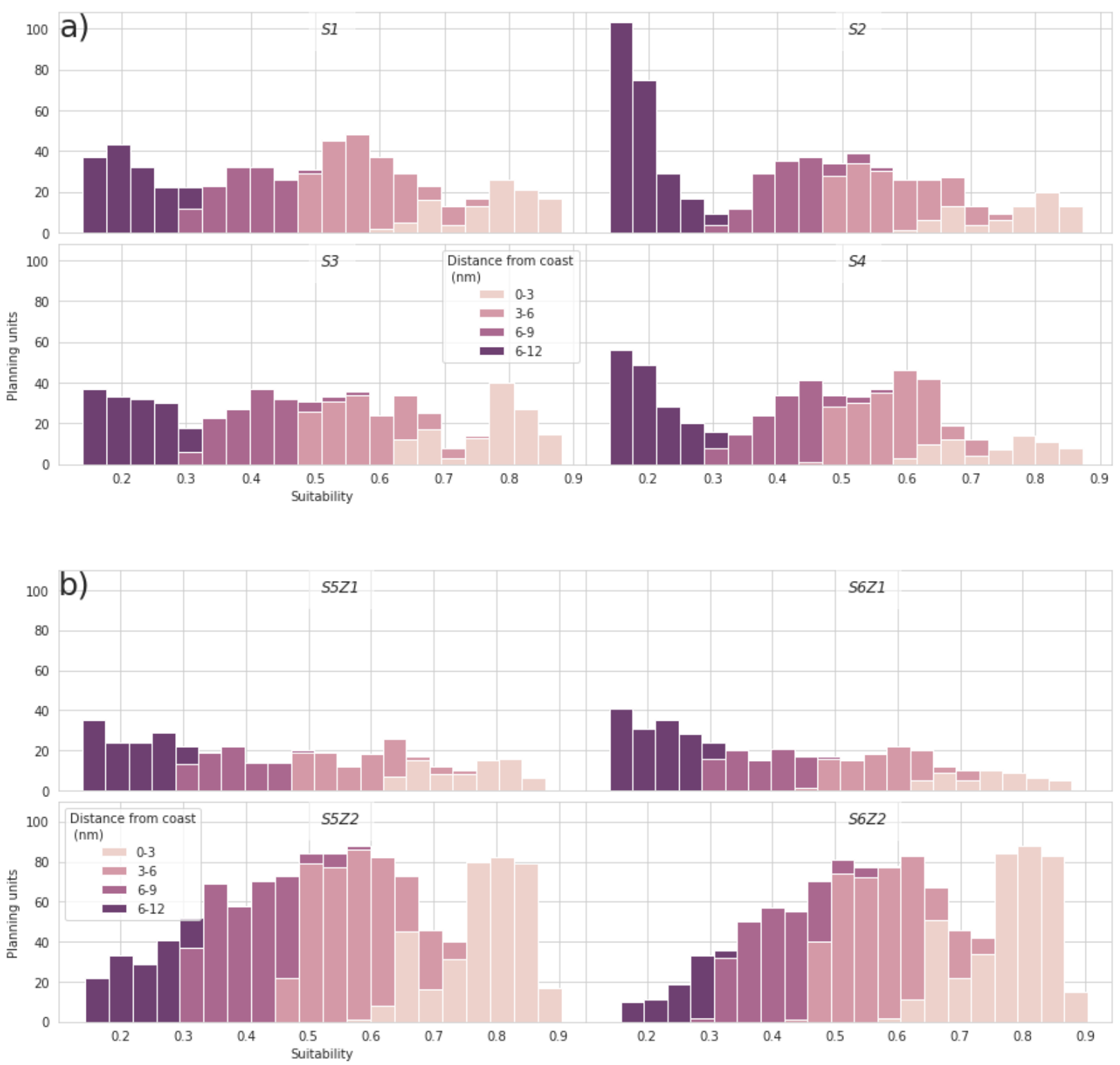

366 Figure 4: Histograms of the number of selected planning as a function of suitability values within $12 \mathrm{~nm}$

367 from the coast taken from the best solutions. Colours represent the distance of the planning unit from the coast. (a) Best solutions of the four Marxan scenarios. (b) Best solutions of the two Marxan with Zones 


\subsection{Scenario comparisons using the spatial pattern analysis}

373 The scatterplot (Figure 5) between NN ratio and the Jaccard ratios for all pairwise comparisons shows that

374 the most similar patterns for prioritized biodiversity are between Scenarios 5 and 6 (scenarios using 375 respectively profitability and suitability surfaces as conservation features) according to the J ratio (0.87)

376 and between Scenarios 2 and 4 (scenarios using respectively profitability and suitability surfaces as costs)

377 according to the NN ratio (0.87). The most dissimilar scenarios are represented by the comparison 378 between S2-S6 (J ratio $=0.99$ and NN ratio $=1.34)$.

380 We found significant NN distances $(p<0.05)$ between all pairwise scenarios except for S1 - S2 $(p=0.14)$.

381 Differently, Jaccard distances are all significant except for S1 - S6 ( $p=0.05)$ and S2 - S6 ( $p=0.05)$ (see Figure 3825 and Appendix S.10).

383 Figure 5 shows that NN distances and Jaccard distances are not perfectly correlated so they reflect real 384 differences in similarities. The J ratio is always less than 1 which means all the plans are more similar than 385 random. Jaccard alone is not sufficient to study the comparison among scenarios, NN alone provides a 386 better understanding, the combination of both gives a more solid analysis.

387 According to the NN ratio, three scenario combinations (S2-S4, S5-S6, S1-S4) are more similar than random 388 (NN ratio < 1). Interestingly, analysing similarity relationships on S1, S2, S4, it emerges that scenario S4 is 389 positioned "between" S1 and S2 (S2-S4 $=0.87, \mathrm{~S} 1-\mathrm{S} 4=0.95, \mathrm{~S} 1-\mathrm{S} 2=0.91)$. This is confirmed by the spatial 
390 distributions (Figure 2), where S1 is quite similar to a random distribution and S2 shows a more defined

391 clustered pattern, with higher aggregation along the coast, as already mentioned. S4 shows an

392 intermediate clustering pattern between the two. So, using the NN ratio, we infer that profitability and

393 suitability surfaces produce similar scenario patterns and thus similar results. Furthermore, no significant

394 similarity is shown between Marxan and Marxan with Zones scenario combinations. However, scenarios

395 S3 and S5, as well as S3 and S6, which use the same cost surface for the biodiversity zone, show a "lower 396 dissimilarity". 


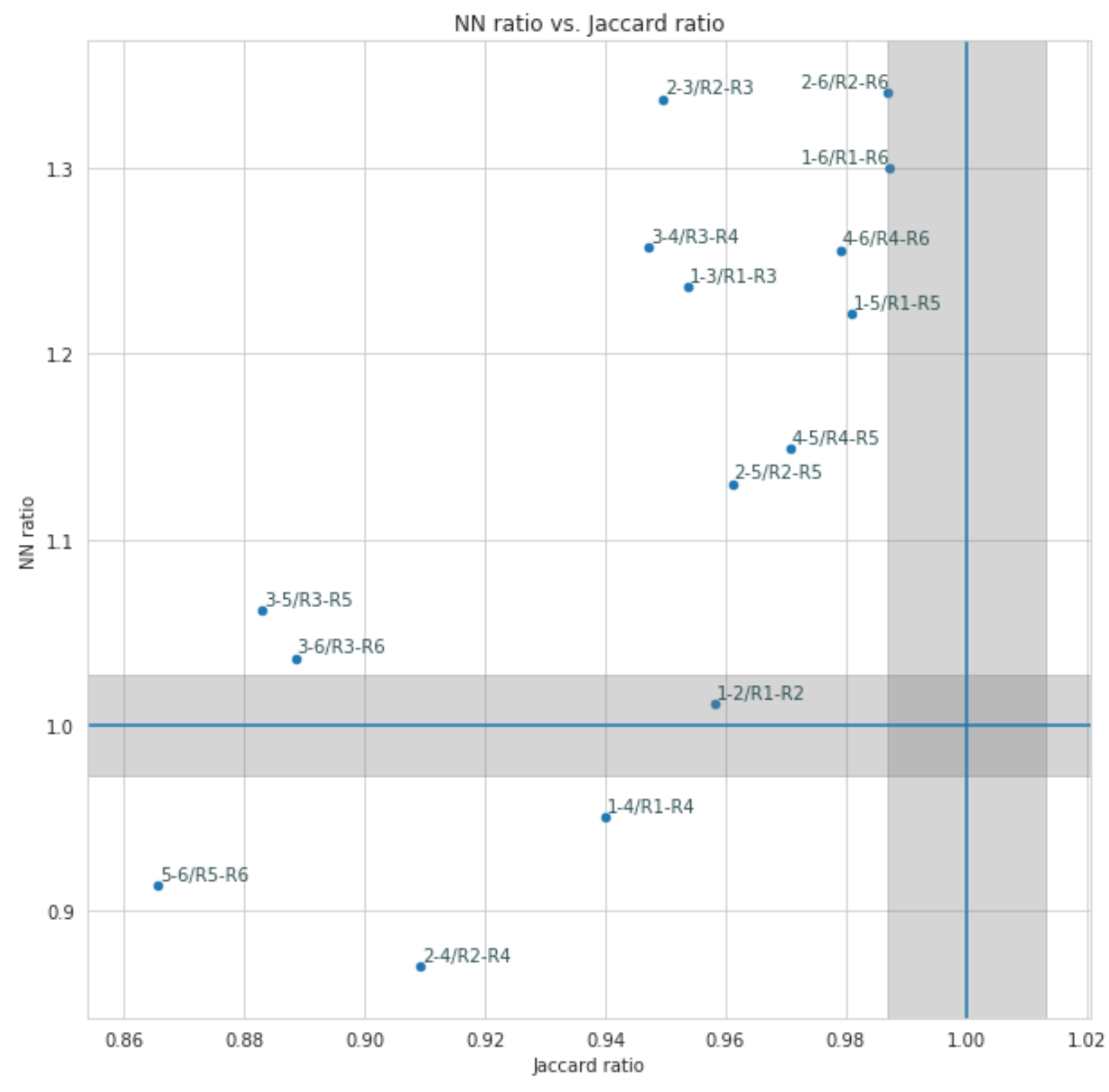

400

401 Figure 5: Scatter plot of NN and J ratios. No confidence interval is shown (grey areas) for a significance 402 level of 0.05

403 


\section{4. Discussion}

405 Marine aquaculture is an increasingly important industry for blue economic growth and food security 406 worldwide (FAO 2015). Yet guidance on how to help countries expand and prioritize zoning for the

407 aquaculture industry alongside biodiversity conservation and other human uses of the sea remains

408 limited. We tested a systematic conservation planning approach for Italy's most economically important

409 mussel farming region, the Emilia-Romagna. We were particularly interested in how variations in the

410 socio-economic data used, and how they were considered (e.g. either as costs to be minimized (Marxan)

411 or features to prioritize (Marxan with Zones)), influenced spatial zoning priorities. We found that planning

412 for both biodiversity and aquaculture simultaneously resulted in more efficient conservation zones placed

413 in areas less likely to generate conflict with other human uses, including aquaculture. Additionally, higher

414 quality suitable habitat was retained for aquaculture zoning compared to when biodiversity alone was

415 prioritized in an effort to minimize conflict with industries. Thus, we advocate for the integration of multi-

416 objective seascape zoning to improve efficiency and minimize conflicts when industry and conservation

417 are both considered parts of blue economic growth strategies. Further, embedding multi-objective 418 optimization and decision-support tools into blue economy frameworks will help planners and 419 stakeholders better understand the trade-offs between objectives that need to reconcile critical 420 biodiversity protection, food production and economic growth.

422 In the Emilia-Romagna region, we found there is ample space to grow the aquaculture sector without 423 compromising biodiversity objectives for habitats and the pelagic species in the region. Minimizing 424 impacts with other industries should also be feasible as the majority of industries in direct conflict with 425 mussel aquaculture tend to be spatially discrete and distributed further offshore from where the most 426 suitable coastal conditions are for mussel farms (Appendix S5.b). We suggest using the results from 
427 Scenario 6 as the foundation for discussions with stakeholders to further determine the most appropriate

428 and cost-effective placement of mussel farms and MPAs within the broader zones identified.

430 We did not quantify the potential negative impacts from bivalve farms on the surrounding biodiversity as

431 part of this study. However, these impacts can be accommodated in the multi-objective zoning approach

432 using Marxan with Zones. This will be particularly important for integrated zoning for aquaculture species

433 that are known for causing more substantial environmental impacts (e.g. carnivorous crustaceans and

434 marine fish (Primavera 2006)).

436 An important part of our analysis was developing a fine-scale suitability surface for the target aquaculture

437 species. It takes a long time and substantial resources to gather the environmental and biophysical

438 characteristics of the region, as well as validating weightings with regional experts on the ecological and

439 socio-economic parameters affecting suitability (Dapueto et al. 2015). Given the investment in time and

440 resources required to generate this suitability surface (S6), approximately 3 months FTE for 3 scientists

441 (analysis simple from a computational point of view, timing mainly due to literature analysis and data

442 processing, most of the data already available, but not all, no timing from expert considered, since we rely

443 on Dapueto et al. 2015), we also wanted to retrospectively understand the value of that information to

444 inform the optimization compared to the proxy distance surface computed in less than 1 hour in a

445 Geographic Information System - the profitability surface (S5). Value of information theory frames the

446 investments scientists make in data collection in terms of its ability to help managers make better

447 decisions (McGowan et al. 2017). In spatial planning, value of information can help us direct limited

448 resources towards collected data where it will reduce key uncertainties in our knowledge of marine

449 ecosystem processes, and subsequently, impact or change what emerges as priority areas (Mazor et al.

450 2016). 
452 In this instance, the value of fine scale suitability information (S6) resulted in an $8 \%$ increase in efficiency

453 for the areas prioritized for aquaculture compared to the simpler profitability surface (S5). These two

454 scenarios, which prioritized aquaculture alongside biodiversity in the multi-objective zoning approach,

455 also produced the most similar spatial solutions than any pairwise comparison (Figure 5). We conclude

456 that the return on investment for the time and resources to generate the more realistic suitability surface

457 was significant but marginal (Appendix S4a-b), highlighting that when multi-criteria approaches to define

458 suitability include socio-economic factors or other operational constraints (e.g. distance to coastlines or

459 port) with high weightings assigned to them, a proxy surface may provide sufficient information to

460 properly inform the optimization and save valuable time and resources. However, we recognize that this

461 finding is also dependent on the fact that the ecological parameters did not vary widely across our

462 planning region - we anticipate the value of fine-scale suitability modelling to alter the priorities in places

463 with higher oceanographic and water quality variability.

465 The comparative statistical methods we apply (projection of the suitability onto different scenarios, 466 histograms distributions, Jaccard, Nearest Neighbors) are consistent in demonstrating significant 467 similarity between two pairs of scenarios: S5 and S6, S2 and S4, where S5 and S6 are multi-objectives 468 scenarios respectively with aquaculture profitability and suitability as conservation features, while S2 and 469 S4 are biodiversity prioritization scenarios respectively with aquaculture profitability and suitability as 470 costs.

471 According to our statistical analysis (histograms and ratios), the S5 and S6 spatial plans are very similar. In 472 these scenarios, the introduction of an aquaculture zone, allows us to obtain better results in terms of the 473 trade-off between aquaculture and biodiversity (statistics show good capacity to avoid areas of high 474 suitability). 
475 Plans S2 and S4 were expected to be similar because the aquaculture suitability has been built with strong

476 emphasis on socio-economics. However statistical analysis reveals that plan S4 is preferable because of 477 the more detailed socio-economic modelling.

479 However, the difference in using profitability and suitability is less marked in S5 and S6 in line with 480 crossplot output and also consistent with the distance between S5 and S6, which is lower than that one 481 between S2 and S4.

482

\section{Conclusion}

484 We provide practical guidance on how to conduct and evaluate multi-objective spatial prioritization for 485 aquaculture and biodiversity using a systematic planning approach. We believe our overall approach can 486 be adopted to any study where society needs to make trade-offs between biodiversity, aquaculture and 487 other industries. This work is a first step in helping bring aquaculture zoning into the planning dialogue 488 that is taking shape around the world but has yet to see the development of long-term growth strategies 489 (Froelich et al. 2020).

490

491

492 


\section{Author's Contributions}

494 C.V., S.M., H.P., E.G., A.S., A.B. and J.M.C conceived the initial ideas for this work; C.V., S.M., H.P. and 495 J.M.C. developed the methodology; C.V. and A.Z. data acquisition and curation; C.V. initial analysis; C.V 496 and S.M. formal analysis; C.V. and S.M. maps and visualization; C.V. wrote the first draft of the manuscript; 497 H.P. and J.M.C provide major contributions to the analysis and to drafting the text; H.P. and J.M.C 498 supervision; H.P., J.M.C, A.S., A.B, and E.G. funding acquisition; H.P., E.G., D.D., A.S., A.B., and J.M.C. 499 review. All authors contributed critically to the drafts and gave final approval for publication.

\section{Acknowledgements}

503 This research is funded by: RITMARE Flagship Project of the National Research Programmes funded by the

504 Italian Ministry of University and Research (2012-2016); Short Term Mobility (STM) Grants funded by the

505 National Research Council of Italy (2016); Research Grant Program of The Ministry of Research and Higher

506 Education of Indonesia in academic year 2017/2018 and by the Erasmus Mundus Master Course on

507 Maritime Spatial Planning of the Education, Audiovisual and Culture Executive Agency (EACEA) (GA 2016-

$508 \quad 1889$ and 2017-1725).

509 


\section{Data Availability}

512 Data available from the Zenodo Repository https://doi.org/10.5281/zenodo.4279386 (Venier et

513 al., 2020).

514

\section{Bibliography}

516

517 Andersen, J. H. (2013). Human uses, pressures and impacts in the eastern North Sea. 139.

518 ARPAE. (2017). Monitoraggio delle acque marino costiere e classificazione dello stato di qualità-

519 Rapporto triennale 2014-2016. https://webbook.arpae.it/indicatore/Stato-ecologico-delle-acque-

520 marino-costiere-00001/?id=ea6592b6-5a44-11e6-8eeb-11c9866a0f33

521 Assomineraria. (2015). Ricerche Industriali ed Energetiche. Territorio e Idrocarburi in Emilia-Romagna-

522 Quaderno di approfondimento.

523 Ball, I., \& Possingham, H. (2000). Marxan (v1.8.2)-Marine Reserve Design using Spatially Explicit

524 Annealing. A Manual Prepared for The Great Barrier Reef Marine Park Authority, 70.

525 Barbanti, A., Sarretta, A., Venier, C., Depellegrin, D., Bellacicco, S., Farella, G., Menegon, S., et al.. (2018).

526 Fra la terra e il mare: Analisi e proposte per la Pianificazione dello Spazio Marittimo in Emilia-Romagna.

527 Zenodo. https://doi.org/10.5281/zenodo.1184364

528 Beger, M., McGowan, J., Treml, E. A., Green, A. L., White, A. T., Wolff, N. H., Klein, C. J., Mumby, P. J., \&

529 Possingham, H. P. (2015). Integrating regional conservation priorities for multiple objectives into national

530 policy. Nature Communications, 6(1). https://doi.org/10.1038/ncomms9208 
531 CBD (Convention on Biological Diversity)/COP10. (2010). Decision adopted by the conference of the

532 Parties to the Convention on Biological Diversity at its tenth meeting. (The Strategic Plan for Biodiversity

533 2011-2020 and the Aichi Biodiversity Targets.). https://www.cbd.int/doc/decisions/cop-10/cop-10-dec-

534 02-en.pdf

535 Dapueto, G., Massa, F., Costa, S., Cimoli, L., Olivari, E., Chiantore, M., Federici, B., \& Povero, P. (2015). A

536 spatial multi-criteria evaluation for site selection of offshore marine fish farm in the Ligurian Sea, Italy.

537 Ocean \& Coastal Management, 116, 64-77. https://doi.org/10.1016/j.ocecoaman.2015.06.030

538 Davaasuren, N., Brunel, T., Bolman, B., Jak, R., \& Corso, S. (2010). Maps of Europe showing coastal areas

539 (marine ecosystems) with specific characteristics based on physical characteristics and suitability for

540 different activities (p. 46). https://library.wur.nl/WebQuery/wurpubs/fulltext/273159

541 Directorate-General for Maritime Affairs and Fisheries, DG MARE. (2012). Blue Growth: Opportunities for

542 Marine and Maritime Sustainable Growth. Publications Office of the European Union. ISBN 978-92-79-

543 25529-8 https://doi.org/10.2771/43949

544 Ebdon, D. (1991). Statistics in geography: A practical approach-revised with 17 programs. Wiley-Blackwell.

545 European Commission. (2008). Directive 2008/56/EC of the European Parliament and of the Council of 17

546 June 2008 establishing a framework for community action in the field of marine environmental policy

547 (Marine Strategy $\quad$ Framework $\quad$ Directive). $\quad$ https://eur-lex.europa.eu/legal-

548 content/EN/TXT/PDF/?uri=CELEX:32008L0056\&from=EN

549 European Commission. (2014a). Communication from the Commission to the European Parliament, the

550 Council, the European Economic and Social Committee of the Regions concerning the European Union

551 Strategy for the Adriatic and Ionian Region. COM (2014) 357 final.

552 https://ec.europa.eu/regional policy/sources/cooperate/adriat ionian/pdf/com 357 en.pdf 
553 European Commission. (2014b). Directive 2014/89/EC of the European Parliament of the Council of 23

554 July 2014 establishing a framework for maritime spatial planning. https://eur-lex.europa.eu/legal555 content/EN/TXT/PDF/?uri=CELEX:32014L0089\&from=EN

556 European Environmental Agency. (2017). EUNIS habitat classification review 2017.

557 https://www.eea.europa.eu/data-and-maps/data/eunis-habitat-classification\#tab-based-on-data

558 FAO. (2015). Fisheries and aquaculture statistics 2015 (р. 107). http://www.fao.org/3/i7989t/l7989T.pdf

559 Farella, G.; Menegon, S.; Fadini, A.; Depellegrin, D.; Manea, E.; Perini, L.; Barbanti A. (2020). Incorporating

560 Ecosystem Services conservation into a scenario-based MSP framework: an Adriatic case study. Ocean

561 Coast Management 193, 105230. DOI: 10.1016/j.ocecoaman.2020.105230.

562 Fernandes, M. da L., Quintela, A., \& Alves, F. L. (2018). Identifying conservation priority areas to inform 563 maritime spatial planning: A new approach. Science of The Total Environment, 639, 1088-1098. 564 https://doi.org/10.1016/j.scitotenv.2018.05.147

565 Froehlich, H. E., Gentry, R. R., \& Halpern, B. S. (2018). Global change in marine aquaculture production 566 potential under climate change. Nature Ecology \& Evolution, 2(11), $1745-1750$. 567 https://doi.org/10.1038/s41559-018-0669-1

568 Gentry, R. R., Froehlich, H. E., Grimm, D., Kareiva, P., Parke, M., Rust, M., Gaines, S. D., \& Halpern, B. S. 569 (2017). Mapping the global potential for marine aquaculture. Nature Ecology \& Evolution, 1(9), 1317570 1324. https://doi.org/10.1038/s41559-017-0257-9

571 Giakoumi, S., Sini, M., Gerovasileiou, V., Mazor, T., Beher, J., Possingham, H. P., Abdulla, A., Çinar, M. E., 572 Dendrinos, P., Gucu, A. C., Karamanlidis, A. A., Rodic, P., Panayotidis, P., Taskin, E., Jaklin, A., Voultsiadou, 573 E., Webster, C., Zenetos, A., \& Katsanevakis, S. (2013). Ecoregion-Based Conservation Planning in the 
574 Mediterranean: Dealing with Large-Scale Heterogeneity. PLoS ONE, 8(10), e76449. 575 https://doi.org/10.1371/journal.pone.0076449

576 Gissi, E., McGowan, J., Venier, C., Carlo, D. D., Musco, F., Menegon, S., Mackelworth, P., Agardy, T., \&

577 Possingham, H. (2018). Addressing transboundary conservation challenges through marine spatial 578 prioritization: Transboundary Spatial Prioritization. Conservation Biology.

579 https://doi.org/10.1111/cobi.13134

580 Grantham, H. S., Agostini, V. N., Wilson, J., Mangubhai, S., Hidayat, N., Muljadi, A., Muhajir, Rotinsulu, C., 581 Mongdong, M., Beck, M. W., \& Possingham, H. P. (2013). A comparison of zoning analyses to inform the 582 planning of a marine protected area network in Raja Ampat, Indonesia. Marine Policy, 38, 184-194. $583 \quad$ https://doi.org/10.1016/i.marpol.2012.05.035

584 Grati, F., Scarcella, G., Polidori, P., Domenichetti, F., Bolognini, L., Gramolini, R., Vasapollo, C., Giovanardi, 585 O., Raicevich, S., Celić, I., Vrgoč, N., Isajlovic, I., Jenič, A., Marčeta, B., \& Fabi, G. (2013). Multi-annual 586 investigation of the spatial distributions of juvenile and adult sole (Solea solea L.) in the Adriatic Sea 587 (northern Mediterranean). Journal of Sea Research, 84, 122-132. 588 https://doi.org/10.1016/j.seares.2013.05.001

589 Harris, L. R., Watts, M. E., Nel, R., Schoeman, D. S., \& Possingham, H. P. (2014). Using multivariate statistics 590 to explore trade-offs among spatial planning scenarios. Journal of Applied Ecology, 51(6), 1504-1514. $591 \quad$ https://doi.org/10.1111/1365-2664.12345

592 Henriques, N. S., Monteiro, P., Bentes, L., Oliveira, F., Afonso, C. M. L., \& Gonçalves, J. M. S. (2017). Marxan 593 as a zoning tool for development and economic purposed areas-Aquaculture Management Areas 594 (AMAs). Ocean \& Coastal Management, 141, 90-97. https://doi.org/10.1016/i.ocecoaman.2017.03.016

595 Johnson, D. E., Barrio Froján, C., Turner, P. J., Weaver, P., Gunn, V., Dunn, D. C., Halpin, P., Bax, N. J., \& 
Dunstan, P. K. (2018). Reviewing the EBSA process: Improving on success. Marine Policy, 88, 75-85.

Jumin, R., Binson, A., McGowan, J., Magupin, S., Beger, M., Brown, C. J., Possingham, H. P., \& Klein, C.

599 (2018). From Marxan to management: Ocean zoning with stakeholders for Tun Mustapha Park in Sabah,

600 Malaysia. Oryx, 52(04), 775-786. https://doi.org/10.1017/s0030605316001514

601 Klein, C. J., Chan, A., Kircher, L., Cundiff, A. J., Gardner, N., Hrovat, Y., Scholz, A., Kendall, B. E., \& Airamé,

602 S. (2008). Striking a Balance between Biodiversity Conservation and Socioeconomic Viability in the Design

603 of Marine Protected Areas. Conservation Biology, 22(3), 691-700. https://doi.org/10.1111/i.1523-

$604 \quad \underline{1739.2008 .00896 . x}$

605 Klein, Carissa Joy, Steinback, C., Watts, M., Scholz, A. J., \& Possingham, H. P. (2010). Spatial marine zoning 606 for fisheries and conservation. Frontiers in Ecology and the Environment, 8(7), 349-353.

607 https://doi.org/10.1890/090047

608 Mazor, T., Beger, M., McGowan, J., Possingham, H. P., \& Kark, S. (2016). The value of migration

609 information for conservation prioritization of sea turtles in the Mediterranean: Conservation planning of 610 migratory species. Global Ecology and Biogeography, 25(5), 540-552. https://doi.org/10.1111/geb.12434

611 Mazor, T., Possingham, H. P., Edelist, D., Brokovich, E., \& Kark, S. (2014). The Crowded Sea: Incorporating

612 Multiple Marine Activities in Conservation Plans Can Significantly Alter Spatial Priorities. PLoS ONE, 9(8),

613 e104489. https://doi.org/10.1371/journal.pone.0104489

614 McGowan, J., Beger, M., Lewison, R. L., Harcourt, R., Campbell, H., Priest, M., Dwyer, R. G., Lin, H.-Y.,

615 Lentini, P., Dudgeon, C., McMahon, C., Watts, M., \& Possingham, H. P. (2017). Integrating research using 616 animal-borne telemetry with the needs of conservation management. Journal of Applied Ecology, 54(2), 617 423-429. https://doi.org/10.1111/1365-2664.12755 
618 Menegon, S., Depellegrin, D., Farella, G., Sarretta, A., Venier, C., \& Barbanti, A. (2018). Addressing

619 cumulative effects, maritime conflicts and ecosystem services threats through MSP-oriented geospatial

620 webtools. Ocean \& Coastal Management, 163, 417-436.

621 https://doi.org/10.1016/j.ocecoaman.2018.07.009.

622 MIPAAF. (2015). Piano Strategico Nazionale per l'Acquacoltura. http://www.a-m-a.it/wp-

623 content/uploads/2018/02/Allegato 6 PO Piano Strategico Acquacoltura 150928.pdf

624 Naidoo, R., Balmford, A., Ferraro, P., Polasky, S., Ricketts, T., \& Rouget, M. (2006). Integrating economic 625 costs into conservation planning. Trends in Ecology \& Evolution, 21(12), 681-687. 626 https://doi.org/10.1016/j.tree.2006.10.003

627 O’Shea, T., Jones, R., Markham, A., Norell, E., Scott, J., Theuerkauf, S., \& Waters, T. (2019). Towards a blue 628 revolution: Catalyzing private investment in sustainable aquaculture production systems. The Nature 629 Conservancy and Encourage Capital, Arlington, Virginia, USA. 630 https://www.nature.org/content/dam/tnc/nature/en/documents/TNC EncourageCapital TowardsABlu 631 eRevolution FINAL.pdf

632 Primavera, J. H. (2006). Overcoming the impacts of aquaculture on the coastal zone. Ocean \& Coastal 633 Management, 49(9-10), 531-545. https://doi.org/10.1016/i.ocecoaman.2006.06.018

634 Raimund Real and Juan M. Vargas. (1996). The Probabilistic Basis of Jaccard's Index of Similarity. The 635 Probabilistic Basis of Jaccard's Index of Similarity, 45(3), 6. https://doi.org/10.2307/2413572

636 Smith, R. J., Bennun, L., Brooks, T. M., Butchart, S. H. M., Cuttelod, A., Marco, M. D., Ferrier, S., Fishpool, 637 L. D. C., Joppa, L., Juffe-Bignoli, D., Knight, A. T., Lamoreux, J. F., Langhammer, P., Possingham, H. P., 638 Rondinini, C., Visconti, P., Watson, J. E. M., Woodley, S., Boitani, L., ... Scaramuzza, C. A. de M. (2019). 639 Synergies between the key biodiversity area and systematic conservation planning approaches. 
641 Stelzenmüller, V., Gimpel, A., Gopnik, M., \& Gee, K. (2017). Aquaculture Site-Selection and Marine Spatial

642 Planning: The Roles of GIS-Based Tools and Models. In B. H. Buck \& R. Langan (Eds.), Aquaculture

643 Perspective of Multi-Use Sites in the Open Ocean (pp. 131-148). Springer International Publishing.

644 https://doi.org/10.1007/978-3-319-51159-7 6

645 Valentini, E., Filipponi, F., Nguyen Xuan, A., Passarelli, F., \& Taramelli, A. (2016). Earth Observation for

646 Maritime Spatial Planning: Measuring, Observing and Modeling Marine Environment to Assess Potential

647 Aquaculture Sites. Sustainability, 8(6), 519. https://doi.org/10.3390/su8060519

648 Venier Chiara, Menegon Stefano, Zanella Andrea, \& McGowan Jennifer. (2020). Marxan and Marxan with

649 Zones input datasets for Multi-objective zoning for aquaculture and biodiversity in Emilia-Romagna

650 Region [Data set]. Zenodo. https://doi.org/10.5281/zenodo.4279386

651 Watts, M. E., Ball, I. R., Stewart, R. S., Klein, C. J., Wilson, K., Steinback, C., Lourival, R., Kircher, L., \&

652 Possingham, H. P. (2009). Marxan with Zones: Software for optimal conservation based land- and sea-use

653 zoning. Environmental Modelling \& Software, 24(12), 1513-1521.

$654 \quad$ https://doi.org/10.1016/j.envsoft.2009.06.005

655 Yates, K. L., Schoeman, D. S., \& Klein, C. J. (2015). Ocean zoning for conservation, fisheries and marine 656 renewable energy: Assessing trade-offs and co-location opportunities. Journal of Environmental 657 Management, 152, 201-209. https://doi.org/10.1016/j.jenvman.2015.01.045 